\title{
The population history of the Croatian linguistic minority of Molise (southern Italy): a maternal view
}

\author{
Carla Babalini, Cristina Martínez-Labarga, Helle-Viivi Tolk, Toomas Kivisild, Rita \\ Giampaolo, Tiziana Tarsi, Irene Contini, Lovorka Barać, Branka Janićijević, Irena Martinović \\ Klarić, Marijana Peričić, Anita Sujoldžić, Richard Villems, Gianfranco Biondi, Pavao Rudan \\ and Olga Rickards
}

European Journal of Human Genetics (2006) 14, 1059. doi:10.1038/sj.ejhg.5201703

Correction to: European Journal of Human Genetics (2005) 13, 902-912. doi:10.1038/sj.ejhg.5201439; published online 11 May 2005

Since publication of the above paper, the authors have noticed an error in Table 2 of the supplementary information. The sample CAM1260 was erroneously classified as T2 instead of $\mathrm{J}$ (the sample presents mutations at 16069 and 16126, and $+10394 c$, $+4216 q)$. Moreover, after a thorough reanalysis, the sample PU1419 turned out to be CRS at HVS-I. A corrected version of the table is now available at the EJHG web site linked to this corrigendum.

The authors are grateful to Walther Parson for bringing the mistakes to their attention.

\section{Meta-analysis of TNF- $\alpha$ promoter $-308 \mathrm{~A} / \mathrm{G}$ polymorphism and SLE susceptibility}

\author{
Young Ho Lee, John B Harley and Swapan K Nath \\ European Journal of Human Genetics (2006) 14, 1059-1060. doi:10.1038/sj.ejhg.5201705
}

Correction to: European Journal of Human Genetics (2006) 14, 364-371. doi:10.1038/sj.ejhg.5201566; published online 18 January 2006

The authors have identified an error in the above article. The largest and most powerful study that has been done to date $^{1}$ was omitted in Tables 1 and 2. Correa et al ${ }^{1}$ was published after the original submission and before the acceptance of a revised version of the above article, and was unfortunately not included in the final article. The data in the study were important for the meta-analysis, and the inclusion of Correa et al's results does not alter the conclusions of the paper, but makes them stronger. The authors regret this error.

\section{Reference}

1 Correa PA, Gomez LM, Cadena J, Anaya JM: Autoimmunity and tuberculosis. Opposite association with TNF polymorphism. J Rheumatol 2005; 32: 219-224. 